\title{
Congenital diaphragmatic hernia with probable autosomal recessive inheritance in an extended consanguineous Pakistani pedigree
}

\author{
S J Mitchell, T Cole, D H A Redford
}

\begin{abstract}
We report four cases of congenital diaphragmatic hernia occurring in two generations of a consanguineous Pakistani family. The affected subjects resembled no recognised genetic syndrome. This family provides further evidence for possible autosomal recessive inheritance of congenital diaphragmatic hernia in some cases.
\end{abstract}

$(\mathcal{H}$ Med Genet 1997;34:601-603)

Keywords: diaphragmatic hernia; recessive inheritance

Congenital diaphragmatic hernia is a relatively common congenital abnormality with a high mortality and morbidity. Isolated congenital diaphragmatic hernia is generally considered as a sporadic event, although a number of affected sibs have been described and there have been a small number of reports of apparent familial cases in whom autosomal recessive inheritance has been postulated. Four cases, one female and three male, are reported of congenital diaphragmatic hernia occurring in three related sibships within a large Pakistani family (fig 1). In all cases, the parents of affected subjects were first cousins and there is extensive remote consanguinity within the pedigree. Autosomal recessive inheritance seems likely.
Neonatal Unit,

Birmingham Women's

Hospital, Edgbaston,

Birmingham B15 2TG, UK

S J Mitchell

Clinical Genetics Unit, Birmingham Women's Hospital, Edgbaston,

Birmingham B15 2TG, UK

T Cole

Department of

Obstetrics, Royal

Shrewsbury Hospitals

NHS Trust, Mytton

Oak Road, Shrewsbury

SY3 8XQ, UK

D H A Redford

Correspondence to: Dr Mitchell.

Received 25 November 1996 Revised version accepted for publication 4 February 1997 has remained undiagnosed despite exhaustive investigations.

\section{CASE 2 (IV.3)}

A male infant was stillborn at 32 weeks' gestation. The pregnancy had been complicated by polyhydramnios from 28 weeks of gestation and antenatal ultrasound scans had shown a left sided congenital diaphragmatic hernia. A stillborn male infant was delivered after the spontaneous onset of labour at 32 weeks' gestation. At necropsy, a left sided congenital diaphragmatic hernia was identified with the stomach, small and large bowel, spleen, and pancreas in the left thoracic cavity. There was a large atrial septal defect but no other structural cardiac lesion and no other abnormality was identified. Both maternal and fetal karyotypes were normal.

CASE 3 (IV.1)

A male infant was stillborn at 33 weeks' gestation. A left sided diaphragmatic hernia had been identified prenatally. At necropsy, a large left sided diaphragmatic defect was found, with the spleen, small bowel, and left lobe of the liver present in the left pleural cavity. No other abnormality was identified.

CASE 4 (IV.2) weeks' gestation. A left sided diaphragmatic hernia had been diagnosed prenatally. The baby was in reasonable condition at birth but required ventilation at high pressures to maintain adequate oxygenation. His condition was stabilised and he underwent surgical repair of a left posterolateral congenital diaphragmatic hernia on the second day of life. He made a good postoperative recovery. An echocardiogram showed a structurally normal heart and there were no other abnormal features on clinical examination.

\section{Discussion}

Congenital diaphragmatic defects are a relatively common congenital abnormality with high pre- and postnatal mortality. Four anatomical defects are recognised. The most common is a posterolateral defect (Bochdalek herpleuroperitoneal membrane. This defect occurs with a frequency of around 1 in 2000 births and is five times more common on the left than the right. Bilateral lesions occasionally occur. A retrosternal (Morgagni) hernia may occur owing to failure of development of the
The sib of case 3, a male infant, was born at 38 nia) caused by a failure in development of the other abnormality was detected. Subsequently, two other subjects in this sibship (III.5 and III.6) have presented with a probable autosomal recessively inherited myopathy which 


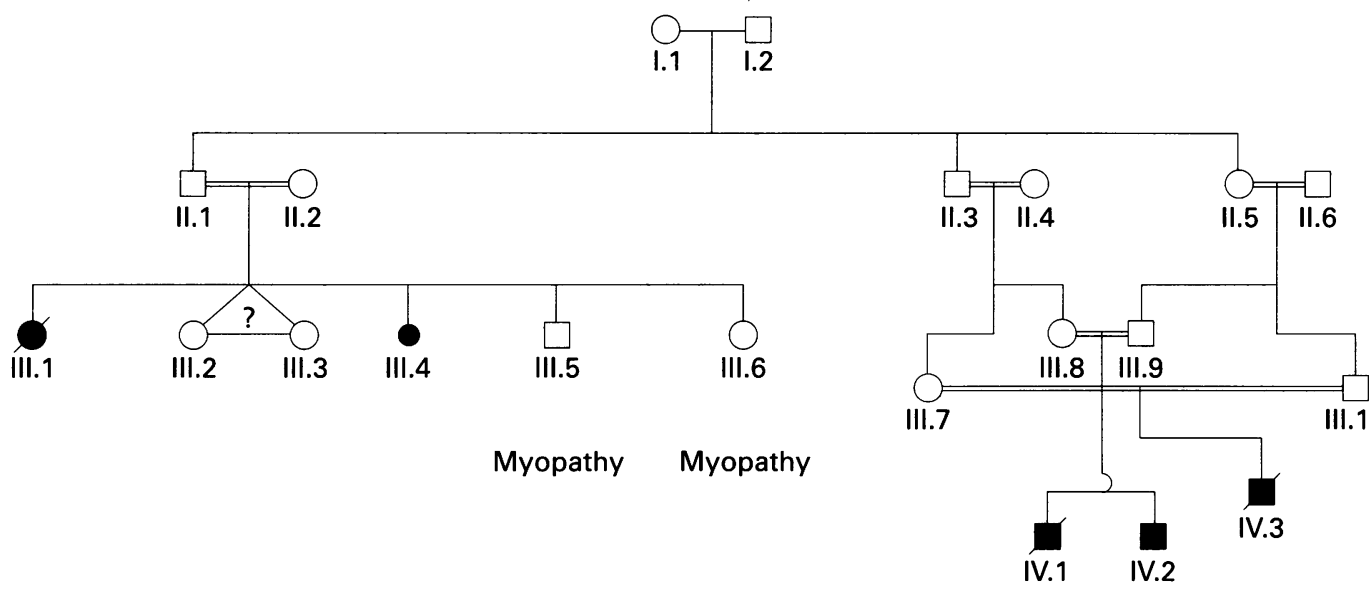

Figure 1 Family pedigree.

septum transversum which gives rise to the central tendon of the diaphragm. These lesions are much rarer with a frequency of around 1 in 100000 births. A hiatal hernia may arise through a failure of fusion of the dorsal mesentery with the stomach leading to a congenitally large oesophageal orifice and herniation of the stomach into the thorax. Finally, eventration of the diaphragm describes a failure of development of the diaphragmatic musculature with ballooning of the aponeurotic sheet upwards into the thorax.

Diaphragmatic defects may occur as an isolated lesion but are frequently associated with other congenital anomalies, particularly cardiac abnormalities and neural tube defects. In addition, a number of multisystem genetic syndromes include diaphragmatic defects in their manifestations. ${ }^{1}$

There have been several published reports of congenital diaphragmatic defects (CDD) occurring in sibs. In 1989, Hitch et al reviewed published reports on sib recurrence of congenital diaphragmatic hernia and concluded that the segregation analysis was most suggestive of autosomal recessive inheritance. However, one report was found of a mother and son with a hiatal diaphragmatic defect and thoracic stomach, both presenting in infancy. ${ }^{3}$ Among recurrent cases in sibs of children with congenital diaphragmatic defects, left sided and bilateral diaphragmatic lesions are most frequently described, together with reports of diaphragmatic aplasia in this group. ${ }^{4}$

To date, five families have been reported in whom there is documented consanguinity and multiple affected subjects with congenital diaphragmatic defects (CDD). Norio et al reported four affected sibs of first cousin Finnish parents who died in the immediate neonatal period with CDD. The diagnosis was confirmed at necropsy in two of the sibs who each showed similar features of a large left sided CDD (subtotal absence of the left hemidiaphragm in one) associated in both with a bicornuate uterus and septate vagina. Farag et $a l^{t}$ reported two sibs of second cousin Jordanian parents who both presented with large left sided CDD (aplasia of the left hemidiaphragm in one) as an isolated defect. The findings were confirmed at necropsy. Arad et al reported two sibs of first cousin Arab parents presenting with a large CDD. In one, there was a left posterolateral CDD with no other abnormalities while the other showed aplasia of both hemidiaphragms and male pseudohermaphroditism. The findings in both were confirmed at necropsy. Farag et $a l^{\beta}$ reported a further six affected sibs in two unrelated consanguineous families. Three sibs of second cousin Kuwaiti parents died in the early neonatal period with CDD. Only one sib underwent a necropsy which showed agenesis of the left hemidiaphragm. Three sibs of first cousin Egyptian parents died in the neonatal period. In the one sib undergoing a necropsy, bilateral posterolateral diaphragmatic defects were found.

In all of the above reports, the parental consanguinity and occurrence of similar defects in often multiple sibs suggests probable autosomal recessive inheritance. The families reported by Norio et $a \bar{l}$ and Arad $e t$ al were distinguished by the presence of associated urogenital abnormalities together with the diaphragmatic defects. It is not clear whether these represent a distinct genetic entity or a variant of that manifesting with isolated diaphragmatic defects.

The cases described in this report resemble no recognised genetic syndrome and would appear to represent autosomal recessive inheritance of a left sided congenital diaphragmatic defect. A possible diagnosis of Fryns syndrome had earlier been discussed, but both liveborn affected infants showed no dysmorphic features and lacked the other associated congenital abnormalities to support this diagnosis. ${ }^{9}$ Two of the affected subjects were shown to have associated cardiac abnormalities. This is a common finding in the presence of a congenital diaphragmatic defect and may be a reflection of the process leading to the defects described, as yet not understood. The natural history of this inherited form of congenital diaphragmatic defect appears similar to that observed in sporadic cases with a high rate of prenatal loss but compatible with survival in those babies who can be stabilised before surgery in the immediate neonatal period.

\section{Conclusions}

The family presented provides further strong evidence for autosomal recessive inheritance of congenital diaphragmatic defects in some 
cases. An overall recurrence risk of around 1\% has been estimated for the sibs of a child with a congenital diaphragmatic defect ${ }^{10}$ and it has been been suggested that cases without other associated abnormalities may be at a greater risk of recurrence. ${ }^{11}$ However, in consanguineous couples with one affected child, higher recurrence risks may be appropriate than those currently given and additional pre- and perinatal surveillance and management is warranted.

We thank Dr M S Hoque and Mr B Bentick for providing information relating to their patients.

1 Hirata GI, Medaeris AL, Platt LD. Fetal abdominal abnormalities associated with genetic syndromes. Clin Perinatol 1990;17:675-702.

2 Hitch DC, Carson JA, Ide Smith E, Sarale DC, Rennert OM. Familial congenital diaphragmatic hernia is an OM. Familial congenital diaphragmatic hernia is an
autosomal recessive variant. $\Im$ Pediatr Surg $1989 ; 24: 860-4$.
3 Hubert BC, Toyama WM. Familial right thoracic stomach. Pediatrics 1987;79:430-1.

4 Passarge E, Halsy H, German J. Unilateral agenesis of the diaphragm. Humangenetik 1968;5:226-30.

5 Norio R, Kaariainen H, Rapola J. Familial congenital diaphragmatic defects: aspects of etiology, prenatal diagnosis and treatment. Am $\mathcal{F}$ Med Genet 1984;17:471-83.

6 Farag TI, Issa MA, Malfonz ES. Discordant, nonsyndromic, congenital diaphragmatic defects in sibs. $f \mathrm{Med}$ Genet 1989;26:781.

7 Arad I, Lijovertzky GC, Starinsky R, et al. Diaphragmatic defects in children of consanguineous parents. Hum Genet 1980;55:275-7.

8 Farag TI, Bastaki L, Maratie M, Al-Awadi SA, Krsz J. Autosomal recessive congenital diaphragmatic defects in the Arabs. Am f Med Genet 1994;50:300-1.

9 Fryns JP. Fryns syndrome: a variable MCA syndrome with diaphragmatic defects, coarse face, and distal limb hypoplasia. F Med Genet 1987;24:271-4.

10 Czeizel A, Kovacs M. A family study of congenital diaphragmatic defects. Am f Med Genet 1985;21:105-15.

11 Crane JP. Familial congenital diaphragmatic hernia: prenatal diagnostic approach and analysis of twelve families. Clin Genet 1979;16:244-52. 